\title{
Hydrocarboniphaga effusa gen. nov., sp. nov., a novel member of the $\gamma$-Proteobacteria active in alkane and aromatic hydrocarbon degradation
}

Correspondence

Gerben J. Zylstra

zylstra@aesop.rutgers.edu

\author{
Norberto J. Palleroni, Ava M. Port, Hung-Kuang Chang \\ and Gerben J. Zylstra
} Biotechnology Center for Agriculture and the Environment, Rutgers University, New Brunswick,
NJ 08901-8520, USA

\begin{abstract}
Novel alkane-degrading strains of bacteria were isolated from soil contaminated with fuel oil from a leaking underground tank in New Jersey, USA. Two phenotypically similar strains (designated AP102 and $\mathrm{AP}_{103^{\mathrm{T}}}$ ) possessed 16S rRNA sequences unique among the majority of known hydrocarbon-degrading bacteria. The 16S rRNA sequences showed a moderate but distant relationship to the genus Nevskia and a substantial similarity to strains that had previously been isolated for growth on phenol (in Japan) and on toluene (in Canada) by other researchers. The hydrocarbon-degrading strains from Japan, Canada and New Jersey showed no resemblance to the typical morphology of Nevskia but did share a striking similarity among themselves in cell morphology, in the unusual appearance of colonies on various solid media and in various physiological properties. A full taxonomic analysis was performed, including DNA-DNA hybridization and nutritional screening with 117 organic compounds as sole sources of carbon and energy. The strains are active in the degradation of important environmental pollutants, and their phenotypic, physiological, metabolic and genomic properties suggest that they are members of a novel taxon in the $\gamma$-Proteobacteria, for which the name Hydrocarboniphaga gen. nov. is proposed, with the single species Hydrocarboniphaga effusa sp. nov.

The type strain is ${\text { AP } 103^{\top}}^{(=}$ATCC BAA-332 $^{\top}=$ DSM $\left.16095^{\top}\right)$.
\end{abstract}

\section{INTRODUCTION}

Aliphatic and aromatic hydrocarbons are widely prevalent in the environment, the products of natural chemical and physical processes as well as a wide variety of human activities. In addition to natural oil seeps, petroleum and its derivatives are spread throughout the environment via the retrieval, transport, refining and use of fossil fuels, resulting in environmental pollution. It is not surprising therefore that some micro-organisms have adapted to utilize hydrocarbons as their sole sources of carbon and energy for growth. For instance, bacteria of many different genera are known to have the ability for aerobic and anaerobic microbial processes of alkane metabolism.

The four strains of bacteria described here were present in natural materials contaminated with hydrocarbons, and were isolated in three laboratories located distantly from one another. The strains represent a species belonging to

Published online ahead of print on 14 May 2004 as DOI 10.1099/ ijs.0.03016-0.

The GenBank accession numbers for the 16S rRNA gene sequences of strains AP102 and AP103 ${ }^{\top}$ are AY363244 and AY363245, respectively. the $\gamma$-Proteobacteria, with a moderate $16 \mathrm{~S}$ rRNA sequence similarity to the genus Nevskia. This paper gives a description of their properties, from which it is concluded that they are representative of a new genus that we propose to name Hydrocarboniphaga gen. nov. The genomic similarities among the strains suggest that they constitute a single species, which we name Hydrocarboniphaga effusa sp. nov.

\section{METHODS}

Bacterial strains and culture media. Strains AP102 and $\mathrm{AP} 103^{\mathrm{T}}$ were isolated from a soil sample from New Jersey contaminated with heavy fuel oil through the classic enrichment culture technique (Rosenberg, 1992), with dodecane provided in the gas phase as the sole carbon source. For the work described below, only strain $\mathrm{AP} 103^{\mathrm{T}}$ was examined, because the two strains had the same general phenotypic properties and their $16 \mathrm{~S}$ rRNA genes have nearly identical sequences. Strain LX1 was isolated from a compost biofilter in Canada from a bacterial population active in toluene degradation (Juteau et al., 1999). Strains rJ4 and rJ5 were obtained from a Japanese activated sludge, in an enrichment using phenol as the sole carbon source (Watanabe et al., 1999).

The complex media used in our work were trypticase soy agar (Difco), nutrient agar (Difco) and brain heart infusion agar (Difco). The chemically defined medium used in the nutritional screening was described by Palleroni \& Doudoroff (1972) and Palleroni (1984). 


\section{Characterization of the strains}

Morphological observations. Microscopic observations were made and photomicrographs taken with a Leitz Ortholux II microscope with phase-contrast optics. Staining of flagella followed the method of Leifson (1954).

Physiological characterization. Denitrification was determined as described by Stanier et al. (1966). The method of Sierra (1957) was followed for the determination of lipase (Tween 80 hydrolysis) and gelatinase production was tested according to the method of Skerman (1967). Nutritional screening was performed according to Stanier et al. (1966), using the chemically defined medium of Palleroni \& Doudoroff (1972). Carbon substrates were added from filter-sterilized stock solutions to a final concentration of $0 \cdot 1 \%$. Some substrates (alkanes, phenol) were supplied in the gas phase using small tubes with a cotton wick and sealing the plate with Parafilm.

DNA extraction and purification. The procedure of Marmur (1961) was followed for the extraction and purification of DNA used in the determination of DNA base composition and in DNADNA hybridization experiments.

Determination of DNA base composition and of DNA-DNA relatedness. Base composition of the purified DNA was determined by the method of Mesbah et al. (1989). For DNA-DNA hybridization experiments, the S1 nuclease procedure described by Johnson (1994a) was followed. DNA samples of the reference strains were labelled using $\left[{ }^{3} \mathrm{H}\right]$ thymidine and the nick translation procedure, following the instructions given by the kit manufacturer (Invitrogen).

Amplification, cloning and sequencing of 16S rRNA genes. Genomic DNA was isolated using a bacterial total genomic extraction kit (Clontech). The 16S rRNA genes were amplified using the $27 \mathrm{f}$ and $1522 \mathrm{r}$ primers by PCR under standard conditions as recommended by the supplier (Perkin Elmer). The PCR product was purified (Qiagen) and used directly in DNA sequencing reactions (Applied Biosystems) with the primers 27f, 357f, 704f, 926f, 1242f, 342r, 685r, 907r, 1392r and 1522r. Primer sequences are as described by Johnson (1994b). The nucleotide sequences were aligned using CLUSTAL V in the Lasergene software package (DNAStar) and visually inspected. Phylogenetic analysis was performed with the MEGA version 2.1 software package (Kumar et al., 2001). Distances (according to the Kimura two-parameter model) and clustering with the neighbour-joining and maximum-parsimony methods were determined using bootstrap values based on 1000 replications.

\section{RESULTS AND DISCUSSION}

\section{Morphology and colony characteristics}

The four strains (AP103 ${ }^{\mathrm{T}}, \mathrm{LX} 1, \mathrm{rJ} 4$ and $\mathrm{rJ5}$ ) were very similar in their basic morphological characteristics. The cells were small, Gram-negative rods, $0 \cdot 75-0 \cdot 85 \times 1 \cdot 5-2 \mu \mathrm{m}$ (mean $0 \cdot 8 \times 1 \cdot 2 \mu \mathrm{m})$ in size, occurring singly or rarely in short chains. They were motile by means of a single flagellum of polar, subpolar or, more rarely, lateral insertion (Fig. 1). Motility was moderate, usually limited to a few cells in the suspension.

Colonies on different agar media were of irregular shape and smooth when small, but later they became circular, with a wrinkled and folded dome at the centre and a thin margin of somewhat irregular border. The wrinkled appearance appears to be due to the presence of an extracellular product, possibly identical to a capsular material that prevented cell-to-cell contact in dense areas of wet mounts (Fig. 2). The chemical nature of this material has not been investigated.

The colonies were convex with flat edges, where the cells tended to swarm on the agar surface - hence the specific name effusa. Flat colonies composed of cells that swarmed more extensively were produced spontaneously. The extent
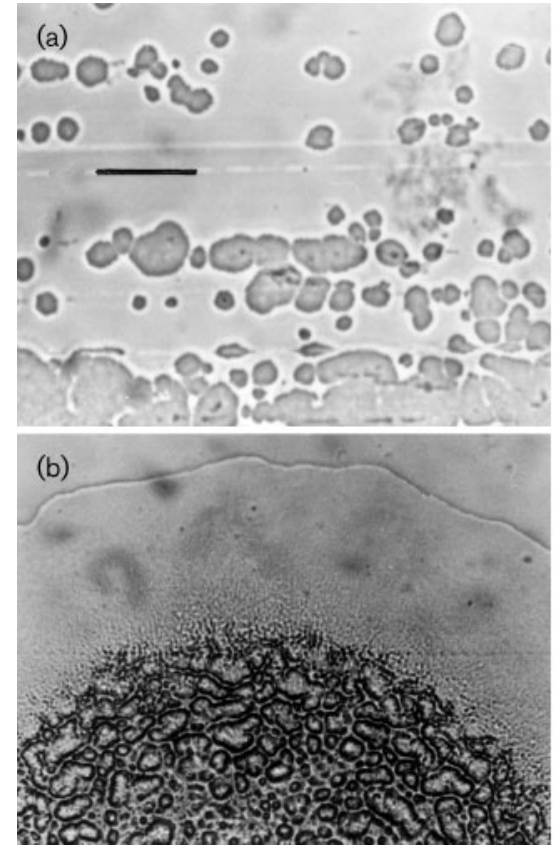

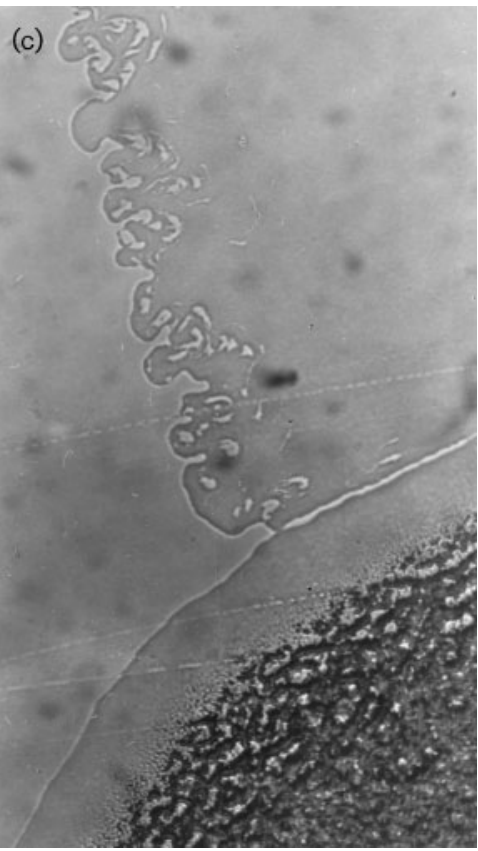

Fig. 1. Colonies of strain $\mathrm{AP}_{103}{ }^{\mathrm{T}}$. (a) Young colonies. (b) Appearance of most colonies near the edge, after 4-5 days of incubation at $28^{\circ} \mathrm{C}$ while growing on minimal medium at the expense of $n$-dodecane. (c) Flat variant colony growing at the edge of a normal colony, showing details of the edge. Bar, $5 \mathrm{~mm}$. 


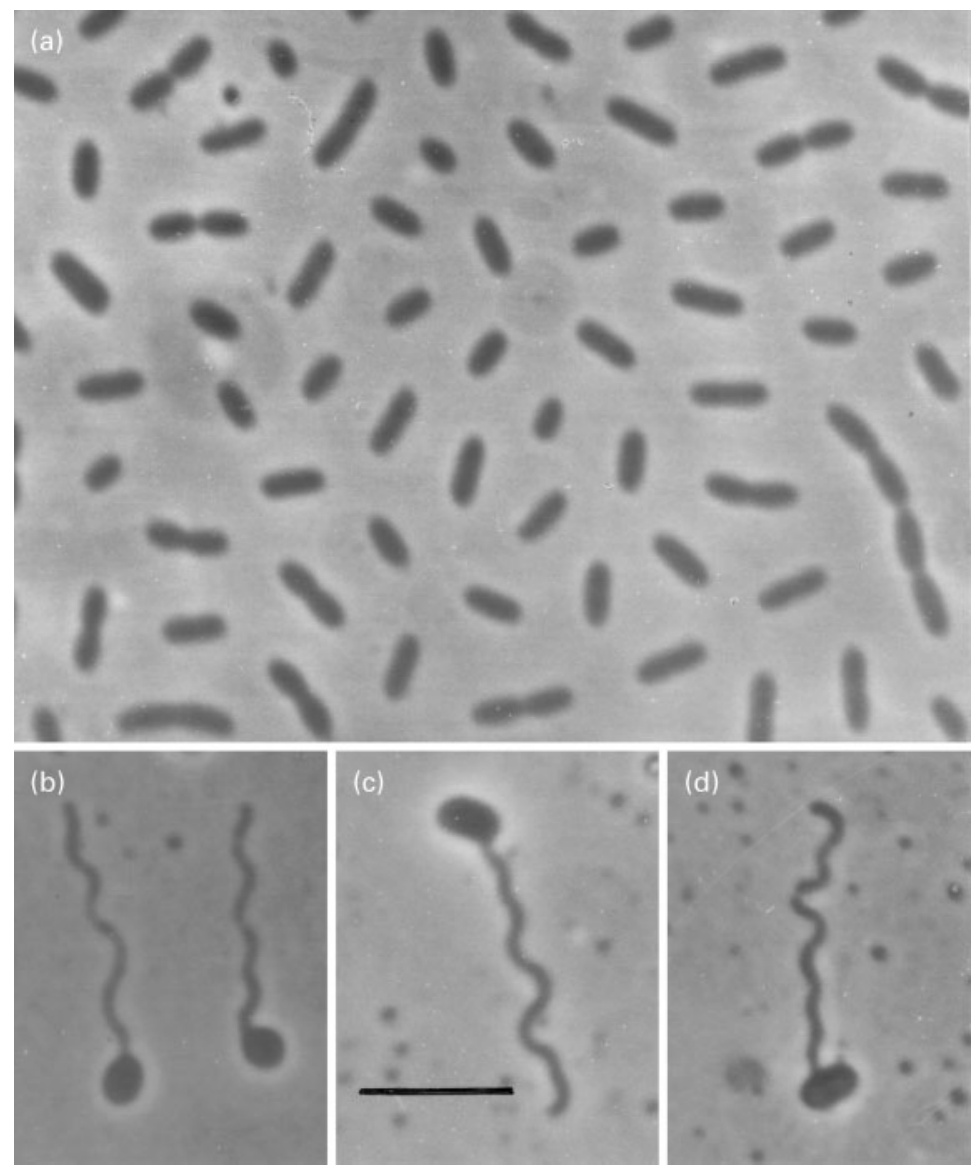

Fig. 2. Cells of strain $A P 103^{\top}$. (a) Phasecontrast. (b-d) Details of flagellar insertion: polar (predominating type) (b), subpolar (c), lateral (d). Bar, $5 \mu \mathrm{m}$.

of swarming varied with the carbon source when the cells were growing on the chemically defined medium. Under these conditions, the production of the flat colony type was relatively common, and a reversion to the normal form was not observed. Twitching motility as the cause of swarming was not investigated.

\section{Physiological properties}

The four strains were absolutely aerobic. The optimal temperature of growth was about $28^{\circ} \mathrm{C}$, with no significant growth seen above about $35^{\circ} \mathrm{C}$. All strains grew on complex media, such as trypticase soy agar, LB medium, nutrient agar and brain heart infusion agar, although growth on the last three media was much slower than on the first. However, the viability of the cells declined rapidly on trypticase soy agar. Viability was considerably longer on a minimal medium recommended for Pseudomonas (Palleroni \& Doudoroff, 1972; Palleroni, 1984) when supplemented with each of a number of carbon sources (see below). Growth on this medium also indicates that organic growth factors are not required.

Ammonium salts or nitrate could be used as nitrogen sources. Denitrification was negative, lipase (Tween 80 hydrolysis) was positive (strains $\mathrm{AP} 103^{\mathrm{T}}$ and LX1 gave a stronger reaction) and gelatinase was positive for $A P 103^{\mathrm{T}}$ and LX1 and very weak for rJ4 and rJ5. The four strains were sensitive to ampicillin, tetracycline and kanamycin and moderately sensitive to chloramphenicol.

Nutritional spectra are given below under the species description. Table 1 summarizes the results obtained with additional substrates that are not utilized by all the strains and are therefore of interest for typing purposes. It is of note that the strains from Japan (rJ4 and rJ5) were nutritionally more versatile, because they grew at the expense of phenol and a number of carbohydrates, among them glucose and saccharides of glucose. Strains AP103 ${ }^{\mathrm{T}}$ and LX1 were negative for these properties. Growth on sucrose by the latter was weak, presumably due to the utilization of the fructose moiety only. An additional difference was seen in the intensities of the gelatinase and lipase (Tween 80 hydrolysis) reactions, which were stronger for $\mathrm{AP} 103^{\mathrm{T}}$ and LX1 than for rJ4 and rJ5.

\section{DNA base composition and DNA-DNA hybridization experiments}

The DNA base composition of strain AP $103^{\mathrm{T}}$ was $60 \mathrm{~mol} \%$ and that of strain rJ5 was $61 \mathrm{~mol} \%$. On the basis of these values, and including formamide in the reaction mixture $(25 \mu \mathrm{l}$ in a total volume of $110 \mu \mathrm{l})$, the reannealing temperature in the DNA-DNA hybridization experiments was set as $66 \cdot 3{ }^{\circ} \mathrm{C}$. In these experiments, the DNA-DNA relatedness of $\mathrm{AP} 103^{\mathrm{T}}, \mathrm{LX} 1, \mathrm{rJ} 4$ and $\mathrm{rJ} 5$ to $\mathrm{AP} 103^{\mathrm{T}}$ was 100 , 
Table 1. Differences in nutritional properties among the strains

+ , Growth; -, no growth; \pm , faint growth after a longer incubation time.

\begin{tabular}{|lcccc|}
\hline Substrate & AP103 $^{\text {T }}$ & LX1 & rJ4 & rJ5 \\
\hline Adonitol & \pm & \pm & + & + \\
D-Arabinose & - & - & \pm & \pm \\
L-Asparagine & \pm & \pm & + & + \\
L-Aspartate & \pm & \pm & + & + \\
Cellobiose & - & - & + & + \\
Glucose & - & - & + & + \\
Glycerol & \pm & \pm & + & + \\
L-Histidine & \pm & \pm & + & + \\
Mannose & \pm & \pm & + & + \\
Phenol & - & - & + & + \\
Propionate & + & + & - & - \\
Raffinose & - & - & + & + \\
Sucrose & \pm & \pm & + & + \\
Trehalose & - & - & + & + \\
Xylose & - & - & \pm & \pm \\
\hline
\end{tabular}

85,84 and $78 \%$, respectively, and to rJ5 was 80, 90, 92 and $100 \%$, respectively.

\section{Phylogenetic analysis}

Near-complete ( $>1450 \mathrm{nt}) 16 \mathrm{~S}$ rRNA gene sequences were determined for $\mathrm{AP} 103^{\mathrm{T}}$ and AP102. A comparison of the 16S rRNA gene sequences for AP103 ${ }^{\mathrm{T}}, \mathrm{AP} 102, \mathrm{rJ} 4, \mathrm{rJ} 5$ and LX1 revealed that they differed in only six locations out of the 1403 positions that were shared among all five sequences. The closest characterized 16S rRNA gene sequence relatives in the GenBank database are those for Nevskia ramosa (Sturmeyer et al., 1998). The three known N. ramosa
$16 \mathrm{~S}$ rRNA gene sequences share approximately $90 \%$ similarity to the five $H$. effusa sequences. Interestingly, the $H$. effusa and $N$. ramosa $16 \mathrm{~S}$ rRNA sequences clustered together and represent a deeply branching lineage in the Xanthomonadaceae (Fig. 3).

\section{Summary}

The strains described in this communication are representative of a new genus, for which we propose the name Hydrocarboniphaga, with the single species Hydrocarboniphaga effusa. The closest known relative based on $16 \mathrm{~S}$ rRNA sequence similarity (about $90 \%$ ) is Nevskia in the $\gamma$-Proteobacteria. However, Hydrocarboniphaga strains can easily be distinguished from Nevskia strains due to the latter's' propensity to form rosette-like colonies at air-water interfaces (Sturmeyer et al., 1998). There is also a significant difference in the $\mathrm{G}+\mathrm{C}$ content of strains of Nevskia (about $68 \mathrm{~mol} \%$ ) and Hydrocarboniphaga (60 mol\%) (Sturmeyer et al., 1998). Nutritionally, Hydrocarboniphaga strains grow on malate and succinate but not acetate, whereas Nevskia strains do not grow on malate or succinate and do grow on acetate (Sturmeyer et al., 1998).

Although the four strains characterized here were all isolated for their ability to grow on hydrocarbons, $16 \mathrm{~S}$ rRNA gene sequence comparisons indicate that $H$. effusa has a wide habitat. Three $H$. effusa-like strains were isolated from sediment from Lake Biwa (Japan) with selection for antibiotic resistance (Miyake et al., 2003; AB074678, AB074679 and AB074686 in Fig. 3). Two 16S rRNA gene sequences from uncultured micro-organisms are included in the dendrogram in Fig. 3. One of these, AY226285, is from a deep-sea hypersaline anoxic basin in the Mediterranean Sea and the other, AB074618, is from a microbial community in the aposymbiotic pea aphid Acyrthosiphon pisum (Nakabachi et al., 2003).

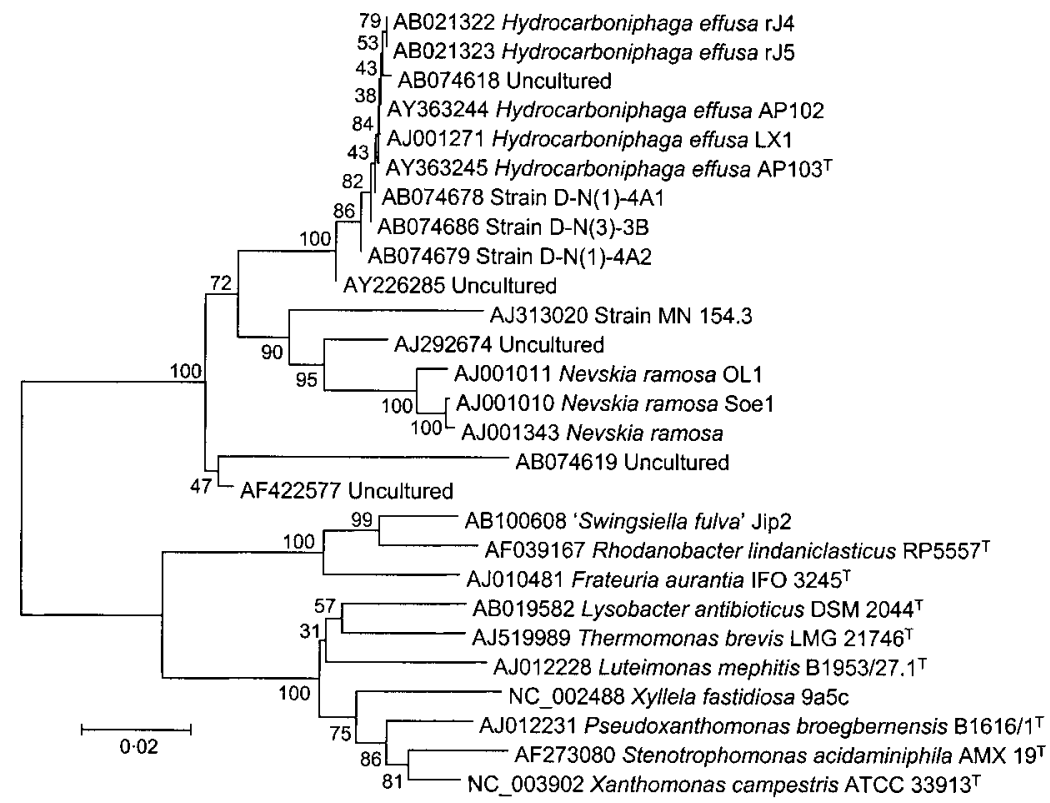

Fig. 3. Unrooted neighbour-joining dendrogram derived from $16 \mathrm{~S}$ rRNA gene sequences showing phylogenetic relationships of $\mathrm{AP}_{103^{\top}}$ and other Hydrocarboniphaga effusa strains, Nevskia ramosa strains and other representative strains in the Xanthomonadaceae. Bootstrap percentages at each node indicate the occurrence in 1000 bootstrapped trees. Bar, genetic distance of 0.02 . 


\section{Description of Hydrocarboniphaga gen. nov.}

Hydrocarboniphaga (Hy.dro.car'bon.i.pha.ga. N.L. n. hydrocarbonum hydrocarbon; Gr. n. phagos eater, devourer; N.L. fem. n. Hydrocarboniphaga eater of hydrocarbons).

Gram-negative rods, $0 \cdot 75-0.85 \times 1 \cdot 5-2 \mu \mathrm{m}$ (mean $0 \cdot 8 \times$ $1 \cdot 2 \mu \mathrm{m}$ ), occurring singly or rarely in short chains, motile by means of a single flagellum of polar or subpolar insertion (Fig. 1). On solid culture media, particularly on those chemically defined, swarming cells at the border cover a large area. The cells are absolutely aerobic and grow well on complex media and on chemically defined media, indicating that they do not require organic growth factors. Ammonium salts or nitrate can be used as nitrogen sources. Denitrification is negative. Gelatinase and lipase (Tween 80 hydrolysis) are positive. The $\mathrm{G}+\mathrm{C}$ content of the DNA is 60-61 mol\% (determined by HPLC). The type and only species is Hydrocarboniphaga effusa.

\section{Description of Hydrocarboniphaga effusa sp. nov.}

Hydrocarboniphaga effusa (ef.fu'sa. L. adj. effusa spreading, diffuse, making reference to the spreading tendency of colonies growing on minimal agar medium).

General morphology and physiological characteristics are given above under the genus description. All strains grow on aliphatic hydrocarbons from C6 to C19, amyl alcohol, L-arginine, 2,3-butylene glycol, erythritol, ethanol, fumarate, L-glutamate, L-isoleucine, DL-lactate, L-leucine, L-malate, mannitol, L-phenylalanine, propylene glycol, pyruvate, L-rhamnose, succinate and L-valine. Growth on butyrate, caprate, caproate and caprylate is slow and very poor. None of the strains uses the following for growth: acetate, aconitate, adipate, L-alanine, $\alpha$-aminobutyrate, $\delta$-aminolaevulinate, amygdalin, $\alpha$-amylamine, anthranilate, arbutin, benzoate, betaine, $n$-butanol, L-citrulline, creatine, creatinine, dipicolinate, dulcitol, ethylene glycol, D-fucose, galactose, gluconate, glucosamine, glucuronate, histamine, $m$-, $o$ or $p$-hydroxybenzoate, 2-ketogluconate, 2ketogulonate, 2-propanol, L-kynurenine, L-lysine, L-lyxose, malonate, maltose, D- or L-mandelate, melibiose, methyl $\alpha$-glucoside, methyl $\alpha$-mannoside, mucate, naphthalene, nicotinate, norleucine, norvaline, pantothenate, L-proline, quinate, saccharate, sarcosine, sebacate, L-serine, sorbose, spermine, D-, meso- or L-tartrate, terephthalate, L-threonine, $o$-, $m$ - or $p$-toluate, turanose or xylitol.

The type strain is $\mathrm{AP} 103^{\mathrm{T}}\left(=\mathrm{ATCC} \mathrm{BAA}-332^{\mathrm{T}}=\mathrm{DSM}\right.$ $\left.16095^{\mathrm{T}}\right)$.

\section{ACKNOWLEDGEMENTS}

We are grateful to M. Häggblom and B. Song for their help in the determination of the $\mathrm{G}+\mathrm{C}$ base composition and helpful discussion and M. Murillo for technical assistance with DNA sequencing. We thank K. Watanabe, D. Rho and P. Juteau for provision of bacterial strains. This work was supported by NSF grant CHE-9810248.

\section{REFERENCES}

Johnson, J. L. (1994a). Similarity analysis of DNAs. In Methods for General and Molecular Bacteriology, pp. 655-682. Edited by P. Gerhardt, R. G. E. Murray, W. A. Wood \& N. R. Krieg. Washington, DC: American Society for Microbiology.

Johnson, J. L. (1994b). Similarity analysis of rRNAs. In Methods for General and Molecular Bacteriology, pp. 683-700. Edited by P. Gerhardt, R. G. E. Murray, W. A. Wood \& N. R. Krieg. Washington, DC: American Society for Microbiology.

Juteau, P., Larocque, R., Rho, D. \& LeDuy, A. (1999). Analysis of the relative abundance of different types of bacteria capable of toluene degradation in a compost biofilter. Appl Microbiol Biotechnol 52, 863-868.

Kumar, S., Tamura, K., Jakobsen, I. B. \& Nei, M. (2001). MEGA2: Molecular Evolutionary Genetics Analysis software. Bioinformatics 17, 1244-1245.

Leifson, E. (1954). The flagellation and taxonomy of species of Acetobacter. Antonie van Leeuwenhoek 20, 102-110.

Marmur, J. (1961). A procedure for the isolation of DNA from microorganisms. J Mol Biol 3, 208-218.

Mesbah, M., Premachandran, U. \& Whitman, W. B. (1989). Precise measurement of the $\mathrm{G}+\mathrm{C}$ content of deoxyribonucleic acid by high-performance liquid chromatography. Int J Syst Bacteriol 39, 159-167.

Miyake, D., Kasahara, Y. \& Morisaki, H. (2003). Distribution and characterization of antibiotic resistant bacteria in the sediment of southern basin of Lake Biwa. Microbes Environ 18, 24-31.

Nakabachi, A., Ishikawa, H. \& Kudo, T. (2003). Extraordinary proliferation of microorganisms in aposymbiotic pea aphids, Acyrthosiphon pisum. J Invertebr Pathol 82, 152-161.

Palleroni, N. J. (1984). Genus I. Pseudomonas Migula 1894. In Bergey's Manual of Systematic Bacteriology, vol. 1, pp. 141-199. Edited by N. R. Krieg \& J. G. Holt. Baltimore: Williams \& Wilkins. Palleroni, N. J. \& Doudoroff, M. (1972). Some properties and subdivisions of the genus Pseudomonas. Annu Rev Phytopathol 10, 73-100.

Rosenberg, E. (1992). The hydrocarbon-oxidizing bacteria. In The Prokaryotes, 2nd edn, pp. 446-459. Edited by A. Balows, H. G. Trüper, M. Dworkin, W. Harder \& K.-H. Schleifer. New York: Springer.

Sierra, G. (1957). A simple method for the detection of lipolytic activity of microorganisms and some observations on the influence of the contact between cells and fatty substrates. Antonie van Leeuwenhoek 23, 15-22.

Skerman, V. B. D. (1967). A Guide to the Identification of the Genera of Bacteria, 2nd edn. Baltimore: Williams \& Wilkins.

Stanier, R. Y., Palleroni, N. J. \& Doudoroff, M. (1966). The aerobic pseudomonads: a taxonomic study. J Gen Microbiol 43, 159-271.

Sturmeyer, H., Overmann, J., Babenzien, H. D. \& Cypionka, H. (1998). Ecophysiological and phylogenetic studies of Nevskia ramosa in pure culture. Appl Environ Microbiol 64, 1890-1894.

Watanabe, K., Teramoto, M. \& Harayama, S. (1999). An outbreak of nonflocculating catabolic populations caused the breakdown of a phenol-digesting activated-sludge process. Appl Environ Microbiol 65, 2813-2819. 